\title{
Photochemical Redox Reaction of Aqueous Benzylpentacyanocobaltate(III)
}

\author{
Arnd Vogler and Renate Hirschmann \\ Institut für Chemie, Universität Regensburg
}

(Z. Naturforsch. 31 b, 1082-1085 [1976]; eingegangen am 28. April 1976)

Redox Reaction, Benzylpentacyanocobaltate(III), Benzyl Radicals, Photochemistry

\begin{abstract}
Charge transfer excitation of aqueous benzylpentacyanocobaltate(III) led to a redox reaction with formation of $\mathrm{Co}(\mathrm{CN})_{5}{ }^{3-}$ and benzyl radicals in the primary photochemical step. In the absence of oxygen the benzyl radicals dimerized to bibenzyl. At $313 \mathrm{~nm}$ irradiating wavelength the quantum yield was $0,13 \pm 0,02$. In the presence of air oxygen was apparently inserted into the carbon-cobalt bond with the intermediate formation of $\left[\mathrm{Co}(\mathrm{CN})_{5} \mathrm{O}_{2} \mathrm{CH}_{2} \mathrm{C}_{6} \mathrm{H}_{5}\right]^{3-}$, which decomposed to give $\mathrm{Co}(\mathrm{CN})_{5} \mathrm{H}_{2} \mathrm{O}^{2-}$ and benzaldehyde $(\Phi=0,15 \pm 0,02)$. The significance of these results is discussed with regard to the photochemistry of acidopentacyanocobaltates(III) and organocobalamins.
\end{abstract}

\section{Introduction}

In contrast to acidopentaammine complexes of $\mathrm{Co}$ (III) the corresponding acidopentacyanides undergo efficient photosubstitution reactions upon ligand field excitation ${ }^{1,2}$. On the other hand, CT (ligand to metal) excitation leads to redox reactions of the ammines with high quantum yields while in the case of the pentacyano complexes the formation of stable redox products has not yet been observed ${ }^{2,3}$. However, it has been shown that CT excitation of acidopentacyanocobaltates(III) is followed by a redox reaction as primary photochemical step 4,5 . The radicals thus produced have been detected by flash photolysis. But a rapid back reaction seems to prevent the formation of stable products. This different photoredox behaviour of the ammine and cyano complexes has been related to the different stability of the metallo fragment, which is generated in the primary photolytic step ${ }^{3}$. $\mathrm{Co}\left(\mathrm{NH}_{3}\right)_{5}{ }^{2+}$ is extremely labile and decomposes in aqueous solution before a reoxidation by the ligand radical takes place. On the other hand $\mathrm{Co}(\mathrm{CN}) 5^{3-}$ is a stable complex and its reoxidation by the ligand radical is very efficient. However, under suitable conditions it should be possible to intercept the primary radicals. Stable redox products may then be formed.

Requests for reprints should be sent to Prof. Dr. Arnd Vogrer, Institut für Chemie der Universität Regensburg, Universitätsstraße, D.8400 Regensburg.
We have explored this possibility and selected the complex ion benzylpentacyanocobaltate(III) for this study. Our expectation, that $\left[\mathrm{Co}(\mathrm{CN})_{5} \mathrm{CH}_{2} \mathrm{C}_{6} \mathrm{H}_{5}\right]^{3-}$ may undergo a photochemical redox reaction, was based on the observation that certain other cobalt(III) complexes containing a cobalt-carbon $\sigma$-bond, particularly organocobalamins and organocobaloximes, undergo a light-induced homolytic splitting of the cobalt-carbon bond ${ }^{7-11}$.

\section{Material}

\section{Experimental}

$\mathrm{Na}_{3}\left[\mathrm{Co}(\mathrm{CN})_{5} \mathrm{CH}_{2} \mathrm{C}_{6} \mathrm{H}_{5}\right] \cdot 2 \mathrm{H}_{2} \mathrm{O}$ was prepared according to a known procedure ${ }^{6}$. The compound was of good spectroscopic purity; its ultraviolet absorption spectrum, shown in Fig. 1, and its IR spectrum agreed well with that reported for an analyzed sample ${ }^{6}$.

\section{Photolysis procedures}

The light source used was a $100 \mathrm{~W}$ Osram highpressure mercury lamp. A Schott filter combination 313 limited the ultraviolet radiation emitted to the wavelength of the mercury line a $313 \mathrm{~nm}$.

The photolyses were carried out at room temperature in $1 \mathrm{~cm}$ cylindrical spectrophotometer cells, using concentrations of complex such as to have essentially complete light absorption (about $\left.2 \times 10^{-4} \mathrm{M}\right)$. Since thermal reactions were slow, corrections were not necessary. The total amount of photolysis was limited to less than $10 \%$ to exclude any possible secondary photolysis or inner filter effects. Absorbed light intensities were determined by ferrioxalate actinometry ${ }^{12}$. 


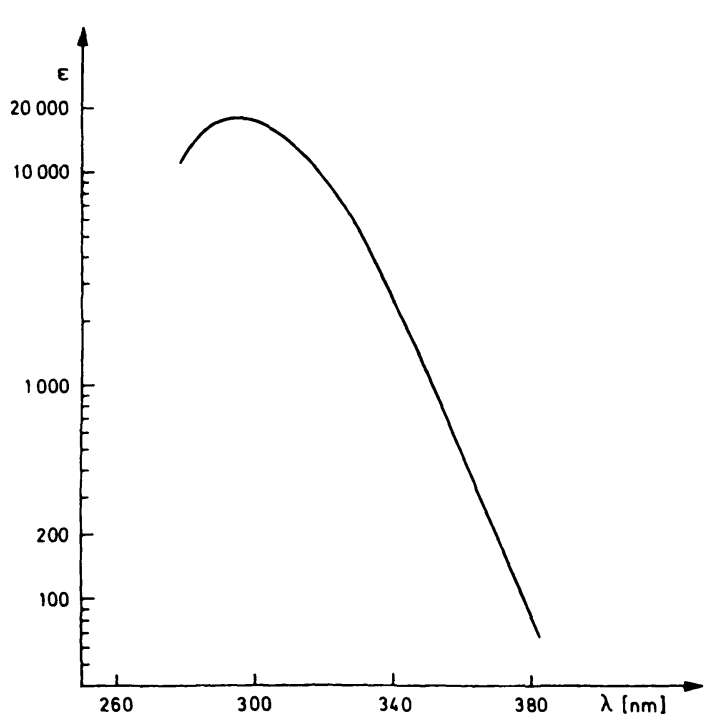

Fig. 1. Absorption spectrum of $\left[\mathrm{Co}(\mathrm{CN})_{5} \mathrm{CH}_{2} \mathrm{C}_{6} \mathrm{H}_{5}\right]^{3-}$.

\section{Measurements}

Infrared spectra were obtained with a Perkin Elmer 325 IR spectrometer. Visible and ultraviolet spectra were measured with a Cary 14 recording spectrophotometer and a Zeiss PMQ II spectrophotometer for measurements at selected wavelengths. Organic photolysis products were identified by gas chromatography (Perkin Elmer F 20 and Varian 1860-42).

\section{Results}

The electronic spectrum of aqueous $\left[\mathrm{Co}(\mathrm{CN})_{5} \mathrm{CH}_{2} \mathrm{C}_{6} \mathrm{H}_{5}\right]^{3-}$

exhibits a single, very intense absorption maximum at $295 \mathrm{~nm}$ with $\varepsilon=1,8 \times 10^{46}$ (Fig. 1). Upon irradiation into this band (313 $\mathrm{nm}$ irradiating wavelength) $\left[\mathrm{Co}(\mathrm{CN})_{5} \mathrm{CH}_{2} \mathrm{C}_{6} \mathrm{H}_{5}\right]^{3-}$, dissolved in deaerated water, underwent a photochemical reaction as indicated by the decrease of the absorption band at $295 \mathrm{~nm}$. Simultaneously a new band appeared at $970 \mathrm{~nm}$ indicating the formation of $\mathrm{Co}(\mathrm{CN})_{5}{ }^{3-13}$. This band was not detected when the photolyzed solution was exposed to air. If the photolysis was carried out in strongly alkaline solution ( $1 \mathrm{M} \mathrm{KOH}$ ) a new intense absorption band occured at $311 \mathrm{~nm}$ when the photolyzed solution was saturated with oxygen. This band is characteristic for the superoxo complex $\left[(\mathrm{NC})_{5} \mathrm{CoO}_{2} \mathrm{Co}(\mathrm{CN})_{5}\right]^{5-}$ which may be formed by aerial oxidation of $\mathrm{Co}(\mathrm{CN})_{5}{ }^{3-14}$. In large scale runs the organic products of the photolysis carried out in neutral, deaerated solutions, were extracted with $\mathrm{CH}_{2} \mathrm{Cl}_{2}$ and identified by gas chromatography. The predominant product (more than $95 \%$ ) was bibenzyl.
On the basis of these results the photolysis took place according to

$$
\begin{aligned}
& 2\left[\mathrm{Co}(\mathrm{CN})_{5} \mathrm{CH}_{2} \mathrm{C}_{6} \mathrm{H}_{5}\right]^{3-} \rightarrow \\
& 2 \mathrm{Co}(\mathrm{CN})_{5}{ }^{3-}+\mathrm{C}_{6} \mathrm{H}_{5} \mathrm{C}_{2} \mathrm{H}_{4} \mathrm{C}_{6} \mathrm{H}_{5} .
\end{aligned}
$$

If light absorption by the starting complex was complete the reaction followed a zeroth order kinetics, since the decrease of the extinction at $295 \mathrm{~nm}$ was proportional to the time of irradiation. At $313 \mathrm{~nm}$ irradiating wavelength the quantum yield was determined by measuring the decrease of the extinction at $295 \mathrm{~nm}$, taking into account that the reaction products have a negligible absorption at $295 \mathrm{~nm}$. The quantum yield was $\Phi=0,13 \pm 0,02$.

When the photolysis was carried out in water in the presence of air the $295 \mathrm{~nm}$ absorption of $\left[\mathrm{Co}(\mathrm{CN})_{5} \mathrm{CH}_{2} \mathrm{C}_{6} \mathrm{H}_{5}\right]^{3-}$ decreased again and the $\mathrm{pH}$ of the solution increased. $\mathrm{Co}(\mathrm{CN})_{5}{ }^{3-}$ was not formed as indicated by the spectrum of the photolyzed solution which did not show the absorption band at $970 \mathrm{~nm}$. This observation is not surprising since $\mathrm{Co}(\mathrm{CN})_{5}{ }^{3-}$ would be oxidized immediately by oxygen with the formation of $(\mathrm{NC})_{5} \mathrm{CoO}_{2} \mathrm{Co}(\mathrm{CN})_{5}{ }^{6-}$. This binuclear peroxo complex is stable only in alkaline solution but should decompose under the reaction conditions ${ }^{14-16}$. Hence the photolysis was carried out in an alkaline solution (1 $\mathrm{M} \mathrm{KOH}$ ) saturated with oxygen. However, neither $\left[(\mathrm{NC})_{5} \mathrm{CoO}_{2} \mathrm{Co}(\mathrm{CN})_{5}\right]^{6-}$ nor the superoxo complex $\left[(\mathrm{NC})_{5} \mathrm{CoO}_{2} \mathrm{Co}(\mathrm{CN})_{5}\right]^{5-}$, which may be formed by further oxidation of the peroxo complex ${ }^{14}$, was formed according to the spectrum of the photolyzed solution, which did not exhibit the typical absorptions of both complexes at $327 \mathrm{~nm}$ or $311 \mathrm{~nm}^{14}$. The organic product of the photolysis in neutral solutions, mainly benzaldehyde, was extracted with $\mathrm{CH}_{2} \mathrm{Cl}_{2}$ and identified by gas chromatography. These results are consistent with the assumption that the photolysis proceeds by an insertion of oxygen into the cobalt-carbon bond with the intermediate formation of a peroxo complex according to

$$
\begin{aligned}
& {\left[\mathrm{Co}(\mathrm{CN})_{5} \mathrm{CH}_{2} \mathrm{C}_{6} \mathrm{H}_{5}\right]^{3-}+\mathrm{O}_{2} \rightarrow} \\
& {\left[\mathrm{Co}(\mathrm{CN})_{5} \mathrm{O}_{2} \mathrm{CH}_{2} \mathrm{C}_{6} \mathrm{H}_{5}\right]^{3-} .}
\end{aligned}
$$

This peroxo complex was apparently not stable under these conditions, but may decompose according to

$$
\begin{aligned}
& {\left[\mathrm{Co}(\mathrm{CN})_{5} \mathrm{O}_{2} \mathrm{CH}_{2} \mathrm{C}_{6} \mathrm{H}_{5}\right]^{3-}+\mathrm{H}_{2} \mathrm{O} \rightarrow} \\
& {\left[\mathrm{Co}(\mathrm{CN})_{5} \mathrm{H}_{2} \mathrm{O}\right]^{2-}+\mathrm{C}_{6} \mathrm{H}_{5} \mathrm{CHO}+\mathrm{OH}^{-} .}
\end{aligned}
$$

Although no attempt was made to detect the complex $\left[\mathrm{Co}(\mathrm{CN})_{5} \mathrm{O}_{2} \mathrm{CH}_{2} \mathrm{C}_{6} \mathrm{H}_{5}\right]^{3-}$, which should have 
been formed intermediately, this is certainly a reasonable conclusion since the formation of peroxo complexes of this type has been demonstrated in related cases ${ }^{17-19}$.

The quantum yield of the disappearance of $\left[\mathrm{Co}(\mathrm{CN})_{5} \mathrm{CH}_{2} \mathrm{C}_{6} \mathrm{H}_{5}\right]^{3-}$, dissolved in air-saturated water, was determined and found to be $\Phi=0,15 \pm 0,02$ $(313 \mathrm{~nm}$ irradiating wavelength). However, this quantum yield may depend on the concentration of oxygen in the solution to be photolyzed.

\section{Discussion}

The electronic spectra of some acidopentacyanocobaltate(III) complexes have been recently investigated ${ }^{20}$. In all cases the lowest spin-allowed transition was of the ligand field type. CT (ligand to metal) bands have been observed at slightly higher energies. The electronic spectrum of aqueous $\left[\mathrm{Co}(\mathrm{CN})_{5} \mathrm{CH}_{2} \mathrm{C}_{6} \mathrm{H}_{5}\right]^{3-}$, shown in Fig. 1, exhibits a single, very intense absorption maximum at $295 \mathrm{~nm}$ $\left(\varepsilon=1,8 \times 10^{4}\right)^{6}$. Since no other band was detected at longer wavelengths, it has been assumed that the first LF band, which should be of low intensity, is hidden under the tail of the $295 \mathrm{~nm}$ absorption. This is certainly a reasonable assumption because an alkyl anion has a high ligand field strength similar to cyanide. The complex $\mathrm{Co}(\mathrm{CN})_{6^{3-}}(312 \mathrm{~nm})^{20}$ as well as $\left[\mathrm{Co}(\mathrm{CN})_{5} \mathrm{CH}_{3}\right]^{3-}(318 \mathrm{~nm})^{6}$ exhibit the first LF bands at comparable energies. The very intense band of $\left[\mathrm{Co}(\mathrm{CN})_{5} \mathrm{CH}_{2} \mathrm{C}_{6} \mathrm{H}_{5}\right]^{3-}$ at $295 \mathrm{~nm}$ was assigned to a $\pi \pi^{*}$ intraligand transition of benzyl ${ }^{6}$ or to a CT transition in the related complex $\left[\mathrm{Cr}\left(\mathrm{H}_{2} \mathrm{O}\right)_{5} \mathrm{CH}_{2} \mathrm{C}_{6} \mathrm{H}_{5}\right]^{2+}(297 \mathrm{~nm}, \varepsilon=7920)^{21}$. The results of the present study and other considerations are consistent with the CT assignment. In benzyl compounds of main group metals, where the electronic structure within the benzyl ligand should be comparable to $\left[\mathrm{Co}(\mathrm{CN})_{5} \mathrm{CH}_{2} \mathrm{C}_{6} \mathrm{H}_{5}\right]^{3-}$, no such highintensity band is observed in this wavelength region ${ }^{22}$. In addition, the lowest $\mathrm{CT}$ (ligand to metal) transitions of acidopentacyanocobaltates(III) occur generally at energies only slightly higher than those of the lowest LF transitions ${ }^{20}$. Particularly the complex $\left[\mathrm{Co}(\mathrm{CN})_{5} \mathrm{CH}_{2} \mathrm{C}_{6} \mathrm{H}_{5}\right]^{3-}$ should have a CT (benzyl to $\mathrm{Co}(\mathrm{III})$ ) transition at low energies due to the strong reducing power of the carbanion ligand. The high intensity of this CT band is consistent with the excitation of a $\sigma$-bonding electron ${ }^{20}$ leading to the homolytic cleavage of the cobalt-carbon $\sigma$-bond.
It was shown that upon irradiation of the absorption band at $295 \mathrm{~nm}$ aqueous $\left[\mathrm{Co}(\mathrm{CN})_{5} \mathrm{CH}_{2} \mathrm{C}_{6} \mathrm{H}_{5}\right]^{3-}$ underwent a redox reaction. Benzyl radicals and $\mathrm{Co}(\mathrm{CN})_{5} 5^{3-}$ were apparently formed in the primary photochemical step. This observation is consistent with our assumption that light absorption into the band at $295 \mathrm{~nm}$ is associated with the excitation of a CT (benzyl to $\mathrm{Co}(\mathrm{III})$ ) state which initiates the photolysis. An excited LF state which may be populated by a radiationless transition from the $\mathrm{CT}$ state initially excited can be excluded as reactive state since LF excitation should lead to an aquation ${ }^{1}$ with formation of $\mathrm{Co}(\mathrm{CN})_{5} \mathrm{H}_{2} \mathrm{O}^{2-}$ and toluene.

The result that $\left[\mathrm{Co}(\mathrm{CN})_{5} \mathrm{CH}_{2} \mathrm{C}_{6} \mathrm{H}_{5}\right]^{3-}$ underwent a photochemical redox reaction does not seem to be surprising since the irradiation of other $\mathrm{Co}$ (III) complexes, containing carbanions as ligands, leads to similar products ${ }^{7-11}$. However, with regard to the photochemistry of acidopentacyanocobaltates(III) ${ }^{1-3}$ the observed photolysis is remarkable since stable redox products were formed. Generally, the redox reaction of acidopentacyanocobaltates(III) which occurs as primary photochemical step, seems to be followed by a rapid reoxidation of the stable complex $\mathrm{Co}(\mathrm{CN})_{5}{ }^{3-}$ by the ligand radical with the subsequent regeneration of the starting complex ${ }^{3-5}$. But in the case of $\mathrm{Co}(\mathrm{CN})_{5} \mathrm{CH}_{2} \mathrm{C}_{6} \mathrm{H}_{5}{ }^{3-}$ the dimerization of the benzyl radicals competes successfully with the back reaction. The newly formed stable carbon-carbon bond of bibenzyl resists then a reduction by $\mathrm{Co}(\mathrm{CN})_{5}{ }^{3-}$, while a dimerization of other ligand radicals as for example the halogens in the case of halopentacyanocobaltates(III) does not lead to products which are stable with respect to the reduction by $\mathrm{Co}(\mathrm{CN})_{5}{ }^{3-}$.

The interception of the benzyl radicals formed in the primary photochemical step does not only take place by the dimerization reaction but also by the insertion of oxygen into the cobalt-carbon bond if air is present.

A further interesting aspect of the present study concerns the nature of the reactive excited state of organocobalamins. The analogy of the photochemical redox reactions of $\left[\mathrm{Co}(\mathrm{CN})_{5} \mathrm{CH}_{2} \mathrm{C}_{6} \mathrm{H}_{5}\right]^{3-}$ and related organocolbalamins ${ }^{7-9}$ suggests that it may be the same type of excited state which is responsible for the photoreactivity. Due to the relatively simple electronic structure it is quite clear that the reactive excited state of $\left[\mathrm{Co}(\mathrm{CN})_{5} \mathrm{CH}_{2} \mathrm{C}_{6} \mathrm{H}_{5}\right]^{3-}$ is of the $\mathrm{CT}$ type. However, such a simple relationship is not 
apparent in the case of organocobalamins. The electronic spectra of cobalamins are determined by the very intense absorptions of the corrin ligand ${ }^{9}$. Any other bands as CT absorptions and LF bands which are of low intensity have not been identified and may be hidden under or obscured by the intense bands which have been assigned to spinallowed $\pi \pi^{*}$ transitions of the corrin ligand. Since the photolysis occurs upon light absorption of the corrin ligand one could assume that an excited state of the corrin ligand is responsible for the photoreactivity. But there is no obvious explanation how an excited state of corrin may initiate a reaction in which the metal center and an axial ligand are involved while the corrin ligand does not participate in these reactions.

The photolysis of organocobaloximes proceeds apparently by the same mechanism as that of the corresponding cobalamin. On the basis of semiempirical calculations it has been suggested that the reactive state is indeed of the CT type ${ }^{11}$. In the case of organocobalamins light absorption of the corrin ligand should then be followed by a radiationless deactivation to a low-lying CT state which initiates the redox reaction. It may be objected that such a CT transition should be seen in the absorption spectrum if it is indeed lower in energy than the lowest $\pi \pi^{*}$ transition of the corrin ligand. However,

1 E. Zinato, "Concepts in Inorganic Photochemistry," Chapter 4, A. W. Anamson and P. D. Fleischauer (eds.), Wiley, New York, N. Y. 1975.

2 V. Balzani and V. Carassiti, "Photochemistry of Coordination Compounds," Chapter 11, Academic Press, New York, N. Y. 1970.

3 J. F. Endicotr, "Concepts in Inorganic Photochemistry," Chapter 3, A. W. Adamson and P. D. Fleischauer (eds.), Wiley, New York, N. Y. 1975.

4 G. Ferraudi and J. F. Endicott, J. Amer. Chem. Soc. 95, 2371 [1973].

5 G. Ferraudi and J. F. Endicott, Inorg. Chem. 12, 2389 [1973].

6 J. Halpern and J. P. Maher, J. Amer. Chem. Soc. 86, 2311 [1964].

7 J. M. Pratt, J. Chem. Soc. 1964, 5154.

8 J. M. Pratt and B. R. D. Whitear, J. Chem. Soc. (A) 1971, 252.

9 J. M. PratT, "Inorganic Chemistry of Vitamin $B_{12}$." Academic Press, New York, 1972, and references cited therein.

10 G. Costa, G. Mestroni, and G. Pellizer, J. Organometal Chem. 15, 187 [1964].

11 G. N. Schrauzer, L. P. Lee, and J. W. Sibert, J. Amer. Chem. Soc. 92, 2997 [1970].

12 C. G. Hatchard and C. A. Parker, Proc. Roy. Soc., Ser. A, 235, 518 [1956].

13 N. N. King and M. E. Winfield, J. Amer. Chem. Soc. 83, $3366[1961]$. the electron distribution within this CT state should lead to large geometrical changes of the complex, particularly to an extension of the axial cobaltcarbon bond due to the Jahn-Teller distortion which occurs in low-spin $\mathrm{Co}(\mathrm{II})$ complexes ${ }^{23}$. As a consequence, although the Franck-Condon transition from the ground state to the CT state can occur at higher energies than that to the lowest $\pi \pi^{*}$ state of the corrin ligand, the potential-energy surface of the CT state may cross that of the lowest $\pi \pi^{*}$ state near the bottom of the latter and extend to lower energies than that of the $\pi \pi^{*}$ state. This would provide a pathway for a radiationless transition from the $\pi \pi^{*}$ state to the reactive CT state. A related suggestion has been made to explain the photochemical behaviour of $\mathrm{Co}\left(\mathrm{NH}_{3}\right)_{5} \mathrm{NO}_{2}{ }^{2+} 24,25$.

It has been recently shown that the photoaquation of cyanocobalamin originates from an excited LF state ${ }^{26}$. It seems that generally the photochemistry of cobalamins is closely related to that of other transition metal complexes and particularly to the photochemical reactions of pentacyano complexes of $\mathrm{Co}(\mathrm{III})^{26}$.

Support for this research by the Deutsche Forschungsgemeinschaft and the Fonds der Chemischen Industrie is gratefully acknowledged. We thank E. Eibler for the analysis of organic products by gas chromatography.

14 J. H. Bayston, R. N. Beale, N. Kelso King, and M. E. Winfield, Aust. J. Chem. 16, 954 [1963].

15 A. Haim and W. K. Wilmarth, J. Amer. Chem. Soc. 83, 509 [1961].

16 J. H. Bayston and M. E. Winfield, J. Catalysis 3, 123 [1964].

17 C. Fontaine, K. N. V. Duong, C. Merienne, A. Gaudemer, and C. Gianotti, J. Organometal. Chem. 38, 167 [1972].

18 C. Gianotti, G. Merle, and J. R. Bolton, J. Organometal. Chem. 99, 145 [1975], and references cited therein.

19 F. R. Jensen and R. C. Kiskis, J. Amer. Chem. Soc. 97, $5825[1975]$.

20 V. M. Miskowski and H. B. Gray, Inorg. Chem. 14, $401[1975]$.

21 J. K. Kochi and D. Davis, J. Amer. Chem. Soc. 86, 5264 [1964].

22 J. Nagy, J. Reffy, A. Kuszmann-Borbely, and K. Palossy-Becker, J. Organometal. Chem. 7, 393 [1967].

23 M. D. Glick, J. M. KuszaJ, and J. F. Endicott, J. Amer. Chem. Soc. 95, 5097 [1973].

24 V. Balzani, R. Ballardini, N. Sabbatini, and L. MogGi, Inorg. Chem. 7, 1398 [1968].

25 F. Scandola, C. Bartocci, and M. A. Scandola, J. Phys. Chem. 78, 572 [1974].

26 A. Vogler, R. Hirschmann, H. Otto, and H. Kun kely, Ber. Bunsenges. Phys. Chem. 80, 420 [1976]. 